\title{
Long-term pegylated interferon- $\alpha$ and its potential in the treatment of melanoma
}

\section{Reinhard Dummer Joanna Mangana}

Department of Dermatology, University Hospital, Zürich, Switzerland
Correspondence: Reinhard Dummer UniversitätsSpital Zürich,

Dermatologische Klinik, Gloriastrasse

3। $\mathrm{CH}-809$ | Zürich, Switzerland

Tel + 4l 44-255 2507

Fax $+4 \mid$ 44-255 8988

Email reinhard.dummer@usz.ch
Abstract: Conventional interferons including interferon- $\alpha$ (IFN- $\alpha$ ) are cytokines used for years in the treatment of solid tumors and hematological malignancies. Their half-life is short. Pegylated forms of IFN- $\alpha$ present an improved pharmacokinetic profile that rendered them the preferred IFNs in hepatitis therapy. In the last decade, pegylated interferons (PegIFNs) have been investigated in melanoma patients. We review the scientific published literature on biology, pharmacokinetics, side effects and clinical applications of PegIFN- $\alpha$ in the treatment of stage III and IV melanoma. In the adjuvant setting, PegIFN $\alpha-2 b$ has significant prolonged distant metastases free survival in patients with microscopic nodal involvement (stage TxN1aM0) and therefore is a promising treatment option in this patient population. In the palliative setting, monotherapy with PegIFN $\alpha-2 \alpha$ can induce complete remissions in a minority of stage IV melanoma patients. The combination of monochemotherapy is feasible and may result in lasting complete remissions. Ongoing research must focus on the identification of patients who mostly benefit, so that unnecessary toxicity would be avoided. Combining PegIFNs and chemotherapy or targeted agents deserves further exploration.

Keywords: interferons, pegylated interferon- $\alpha$, melanoma

\section{Introduction}

\section{Interferons (IFNs) type I and II and their receptors}

Since the discovery of IFNs by Isaacs and Lindemann in $1957,{ }^{1}$ when they were originally described as agents that interfere with influenza virus replication, a tremendous number of studies using predominantly type I IFNs have been conducted. Only in 1978 was IFN purified in amounts that allowed physical and chemical characterization.

IFNs are pleiotropic cytokines. They inhibit viral replication within host-cells through the induction of proteins and activation of specific signaling pathways. ${ }^{2-6}$ Among IFN-induced proteins that affect virus replication is protein kinase $R$ (PKR) which is activated by dsRNA (actually by 2',5' oligoadenylate synthetase, 2,5 OAS). After activation, PKR phosphorylates another protein, the eukaryotic translation initiation factor, eIF2. This factor has reduced ability to initiate translation. Other proteins identified, are the group of Mx proteins, RNase-L nuclease and the RNA-specific adenosine deaminase (ADAR). The ability of IFNs to upregulate major histocompatibility complex 1 (MHC) may also contribute to antiviral response.

IFNs interfere with immune functions by activating natural killer (NK) cells and macrophages, though they protect the unaffected cells from NK cell-mediated lysis, ${ }^{7}$ and they augment antigen presentation to lymphocytes. These activities explain their implications in autoimmunity.

The central role of plasmacytoid dendritic cells (pDCs) to innate antiviral response system by producing type I IFNs has been documented. ${ }^{8,9}$ They regulate and link the adaptive and innate immune response. ${ }^{10,11}$ Human pDCs induce also the production 
of IFN- $\gamma$ in NK cells through interleukin-2 (IL-2) secretion. They express a subset of toll-like-receptors (TLRs), including TLR-7 and TLR-9, which allow them to detect presence of DNA and RNA viruses. ${ }^{12}$ Furthermore, it has been demonstrated that pDCs infiltrate solid tumors. ${ }^{13,14}$ This observation posed intriguing questions about their potency in antitumor response. Recently it has been shown that pDCs are themselves capable of inducing antitumor immunity by activating NK and T cells. ${ }^{15}$

In addition to their antiviral and immunomodulatory effects, IFNs are considered to be antiangiogenic. ${ }^{4,16}$

Recently, the involvement of both IFN type I and II in the elimination phase of cancer immunoediting has been identified. ${ }^{17,18}$ IFN-unresponsive hosts show an increased tumor incidence and the tumors that arise in IFN-unresponsive environments are highly antigenic.

Although first approval was for hairy cell leukemia and for Kaposi sarcoma ${ }^{19}$ they are widely used as a first line therapy in the treatment of many diseases such as chronic hepatitis $C$ and $B$, multiple sclerosis (IFN- $\beta$ ) and melanoma (IFN- $\alpha$ ). Despite the fact that their efficacy has been also demonstrated in other diseases such as follicular non Hodgkin's lymphoma, condylomata acuminata, basal cell carcinoma, chronic phase Philadelphia (PH) chromosomepositive chronic myelogenous leukemia (CML) and renal cell carcinoma ${ }^{20-24}$ they are not regularly used as a first line treatment in these malignancies.

\section{Types of IFNs}

IFNs belong to the large class of glycoproteins known as cytokines. In 1980s IFNs were simply classified in 3 groups: IFN alpha $(\alpha)$, IFN beta $(\beta)$ and IFN gamma $(\gamma) \cdot{ }^{25}$ This categorization was based on antigenic specificity. Today, they are classified according their structural and functional properties in IFN type I, IFN type II and IFN-like cytokines.

\section{Type I IFNs}

There are 13 IFN- $\alpha(\alpha-1, \alpha-2, \alpha-4, \alpha-5, \alpha-6, \alpha-7, \alpha-8$, $\alpha-10, \alpha-13, \alpha-14, \alpha-16, \alpha-17, \alpha-21)^{26}$ members and a single member of each IFN- $\beta$, IFN- $\varepsilon$, IFN- $\kappa$ IFN- $\omega$, IFN- $\delta$ and IFN- $\tau .^{27-29}$ The genes encoding all members of IFN type I family are situated on chromosome $9 .{ }^{30}$

IFNs type I are generally acid stable. IFN- $\alpha$ consists of 165 to166 amino acids, $5 \alpha$ helices which link to a loop (Ab) and 3 shorter segments. ${ }^{31}$ IFN- $\alpha 1$ and IFN-2 $\alpha$ are approximately $80 \%$ homologous but differ overall by 29 amino acids. ${ }^{32,33}$ Although all type I IFNs are secreted in low amounts by all cell types, IFN- $\alpha$ is produced by white blood cells other than lymphocytes.

The molecular structure of the two recombinant IFNs- $2 \alpha$ (IFN $\alpha-2 \alpha$ and IFN- $\alpha 2 b$ ) differs from one another only by one single amino-acid at position $23 .{ }^{34}$ IFN $\alpha-2 \alpha$ and IFN- $\alpha 2 b$ show the same efficacy in the treatment of chronic hepatitis $C$, hairy cell leukemia and Kaposi's sarcoma.

IFN- $\beta$ is a member of type I IFN which consists of 166 amino acids; ${ }^{28}$ it is produced by fibroblasts and it is metabolized in the liver. IFN- $\beta$ is used nowadays for the treatment of multiple scleroses (MS). Two forms of IFN- $\beta$ are used therapeutically.

These forms of IFN- $\beta$ can be produced either in bacterial expression systems (IFN $\beta-1 b)$ or in mammalian cells (IFN $\beta-1 \alpha$ ). They have shown some difference in their structure but their transcriptional response seems to be similar. There is also a difference in their biological response, with the IFN $\beta-1 \alpha$ molecule showing a greater biological potency in its antiviral activity ${ }^{35}$ than IFN $\beta-1 b$. It has been shown that IFN $\beta-1 \alpha$ has an additional benefit of slowing or preventing the development of MS-related brain atrophy. ${ }^{36}$

All type I IFNs exert their biologic activities by binding to a specific cell surface receptor complex, known as the IFN- $\alpha$ receptor (IFN $\alpha-\mathrm{R}$ ). IFN- $\alpha$ receptor is the same for all members of type I IFN family. It consists of a subunit of a $135 \mathrm{kDa}$ IFN $\alpha-R 1$ and of a subunit of $115 \mathrm{kDa}$ INF $\alpha-R 2$ chains. Both receptors are located on chromosome 9. ${ }^{32,37}$ The primary signaling pathway activated by IFNs is the Jak-Stat pathway. ${ }^{38-40}$ The IFN $\alpha-\mathrm{R} 1$ and IFN $\alpha-\mathrm{R} 2$ receptors bind to Janus-activated kinase (Jak) molecules, Tyk2 and Jak1 respectively. ${ }^{41-43}$ Upon binding to its receptors, the receptor undergoes oligomerization, with transphosphorylation of Jaks followed by phosphorylation of the receptor molecule. This leads to activation of signal transducers and activators of transcription (Stats), Stats 1 and Stats 2, which are phosphorylated by the Jaks. The phosphorylated Stats translocate to the nucleus and activate the transcription of IFN - stimulated genes (ISGs). IFN stimulated gene factor 3 (ISGF3) is an important transcription factor which is induced by type I IFNs. ${ }^{44}$

Although IFN- $\alpha$ and IFN- $\beta$ predominantly signal through Stat- 1 and $2,{ }^{45}$ their pathway can involve Stat-3, Stat- 5, Stat-4 and Stat-6. ${ }^{42,46-52}$ Stat 1 plays a prominent role in immune response, while Stat-3 is implicated in tumor progression. Stat 4 and Stat 6 are activated in certain cells, such as endothelial cells and lymphoid cells..$^{50,52}$

Except Jak-Stat other pathways activated by IFNs have been recognized. Of the various mitogen-activated protein 
kinase (MAPK) pathways, p38 signaling has the most important role in the generation of IFN-mediated signals. ${ }^{53-55}$ Other pathways include the phosphatidyl-inositol 3-kinase (PI3K) signaling pathway ${ }^{56}$ and the CRK family of adaptor proteins. ${ }^{57}$ Nevertheless it is now understood that no signaling activation cascade alone is sufficient for the generation of IFN's biological properties. Cooperative function of this network of cytokines is needed for IFN-mediated immune response.

Another member of type I IFN family, IFN- $\kappa$, consists of 207 amino acids, including an amino acid peptide and a series of cysteines conserved in type I IFN. Expression of IFN- $\kappa$ is significantly enhanced in keratinocytes upon viral infection, upon exposure to double-stranded RNA, or upon treatment with either IFN- $\beta$ or IFN- $\gamma \cdot{ }^{36}$

Of the other members of type I IFN family, IFN- $\delta$ is not found in humans and IFN- $\tau$ is found only in ruminant ungulate species. ${ }^{58,59}$ Human IFN- $\varepsilon$ appears to play a role in reproductive function in placental mammals. ${ }^{60}$ Finally IFN- $\omega$ consists of 172 amino acids, displays $60 \%$ similarity to IFN- $\alpha$ and is also produced by leukocytes. ${ }^{28}$

\section{Type II IFNs}

There is only one member of this class of IFNs, IFN- $\gamma^{27,31}$ It is pharmacologically and chemically distinct from type

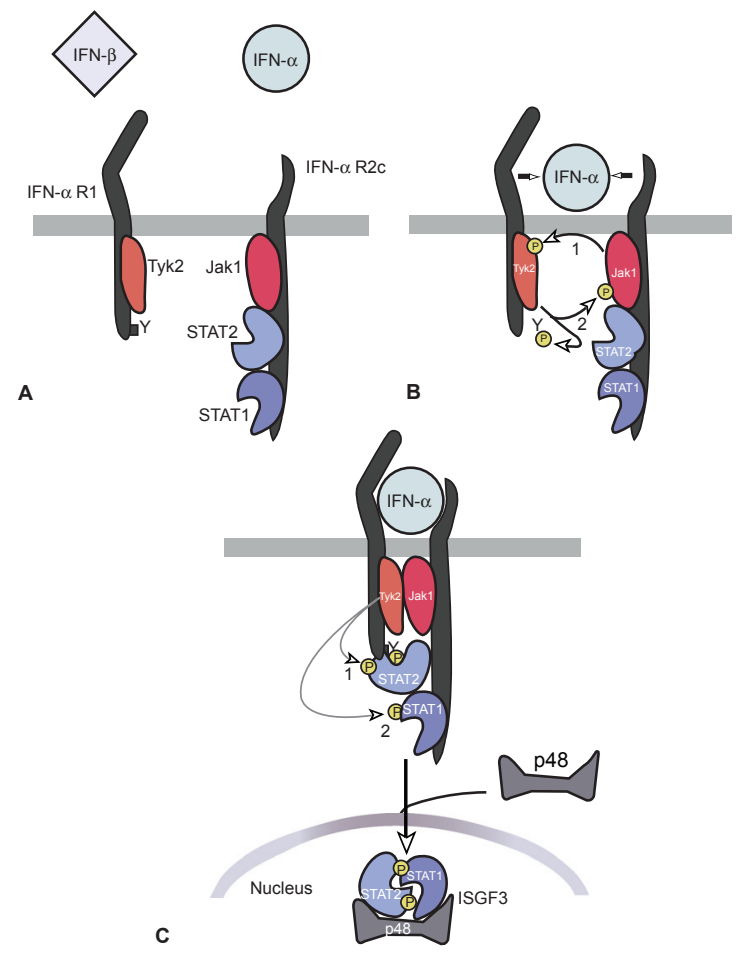

Figure I Signaling pathways activated during engagement of the type I IFN receptor IFN $\alpha-R I$ and IFN $\alpha-R 2$ bind to Tyk2 and JakI respectively. After the phosphorylation of the receptor molecule, signal transducers and activators of transcription (Stats) are activated.
I IFN. IFN- $\gamma$ is a dimerized cytokine produced by NK and $\mathrm{T}$ cells located on human chromosome 12.

IFN- $\gamma$ monomer consists of 140 amino acids and of a core of six-helices with an extended sequence in the C-terminal region. ${ }^{61}$

In contrast to IFN- $\alpha$ and IFN- $\beta$ which can be expressed by all cells, IFN- $\gamma$ can be expressed by T-helpers 1 cells (Th1), Tc cells, NK cells, professional antigen-presenting cells (APCs), B cells and natural killers T cells (NKT). ${ }^{62-65}$ IFN- $\gamma$ is known to enhance neutrophil phagocytosis and microbicidal activity, to induce the expression of fragment crystallizable $(\mathrm{Fc})$ receptor for immunoglobulin $\mathrm{G}(\mathrm{IgG})$ and to exert anti-apoptotic effect on human neutrophils. ${ }^{66}$ Its antitumor, antiviral and immunoregulatory effects have been recognized. ${ }^{67}$ It alters transcription of more than 30 genes with pleiotropic functions.

IFN- $\gamma$ is structurally different from type I IFN, binds to a different receptor and is encoded in a different chromosome. Two receptors have been recognized for IFN- $\gamma$ : IFN $\gamma$-R1 and IFN $\gamma$-R2. These receptors are associated with Jak 1 and Jak 2, respectively. ${ }^{41,68}$ The most important transcription factor of IFN- $\gamma$ is Stat-1. ${ }^{46,47,69,70}$ Stat-1 translocates to nucleus and binds IFN- $\gamma$ activated sequence (GAS) elements to initiate transcription. ${ }^{46,47,69,70}$ IFN- $\gamma$ does not induce the formation of ISGF3 complexes such as type I IFNs.

IFN- $\gamma$ is approved by the US Food and Drug Administration (FDA) for use in chronic granulomatous disease. In Japan IFN- $\gamma$ was registered for cutaneous T-cell lymphoma in $1997 .^{71}$

In conclusion, type I, predominantly IFN- $\alpha$ and IFN- $\beta$, and type II IFNs may signal through distinct pathways and specific cell surface receptors, but exhibit partly overlapping biologic effects particularly through their anti-proliferative activities. ${ }^{69}$

\section{IFN- $\lambda$}

Another group of cytokines, consisting of IL-28 and IL-29, was recognized as a third class of IFNs which are produced by lymphocytes. The genes encoding this family of cytokines are clustered on human chromosome 19. The group consists of three members: IFN $\lambda 1$, IFN $\lambda 2$ and IFN $\lambda 3$. The group expresses its activity by signaling through a receptor complex consisting of IL10R2 (also designated as CRF2-4) and IFN $\lambda$-R1 (also designated as CRF2-12). ${ }^{30}$

\section{Pharmacokinetics of IFN- $\alpha$}

IFN- $\alpha$ are suitable for intravenous (iv), intramuscular (im) and subcutaneous (sc) administration. They are not absorbed 
orally, since they are degraded in the gastrointestinal tract. ${ }^{72}$ IFN- $\alpha$ undergo proteolytic degradation during renal tubular re-absorption causing a negligible amount to remain in systemic circulation.

After a 36 million international units (MIU) iv infusion of recombinant IFN $\alpha-2 \alpha($ rIFN $\alpha-2 \alpha)\left(\right.$ Roferon $\left.^{\circledR}\right)$ in healthy people, an elimination half-life of 3.7 to 8.5 hours (mean 5.1 hours), volume of distribution at steady-state of 0.223 to $0.748 \mathrm{~L} / \mathrm{kg}$ (mean $0.4 \mathrm{~L} / \mathrm{kg}$ ) and a total body clearance of 2.14 to $3.62 \mathrm{~mL} / \mathrm{min} / \mathrm{kg}$ (mean $2.79 \mathrm{~mL} / \mathrm{min} / \mathrm{kg}$ ) was exhibited. ${ }^{72}$

There was no significant difference between the pharmacokinetics of rIFN $\alpha-2 \alpha$ after single im dose in patients with disseminated cancer and healthy volunteers. ${ }^{72}$

There were no changes in the distribution or elimination of rIFN $\alpha-2 \alpha$ during twice daily ( 0.5 to 36 million IU), once daily ( 1 to 54 million IU), or 3 times weekly ( 1 to 136 million IU) dosing regimens up to 28 days of dosing. Multiple im doses of rIFN $\alpha-2 \alpha$ resulted in an accumulation of 2 to 4 times of the single dose serum concentrations. ${ }^{72}$

In a study of 12 males, the elimination half-life following sc or im injections of IFN $\alpha-2 b$ (Intron ${ }^{\circledR} A$ ) was approximately 2 hours. $^{73}$

\section{IFN biomarkers and resistance}

A number of surrogate markers have been investigated in order to define the dose-response relationship of IFN- $\alpha$. 2,5 OAS, an enzyme induced by both IFN- $\alpha$ and IFN- $\gamma$, seems to play a role in IFN response. Increased levels of this enzyme were shown to correlate with decreased cell cycling in melanoma cell cultures treated with IFN. ${ }^{74}$ Other markers such as neopterin and $\beta 2$ microglobulin were used to evaluate this hypothesis. Studies in melanoma ${ }^{75-77}$ provide conflicting data on the utility of neopterin levels in predicting response to immunotherapy. In aggregate, these markers may show laboratory confirmation of stimulation of IFN, but do not provide consistent predictive information on the outcome of IFN therapy.

Another protein, Mx protein, associated with antiviral properties of IFN therapy, specifically type I and II IFN in vivo and in vitro, has been identified. ${ }^{78}$ The $\mathrm{Mx}$ family, a subclass of high-molecular-weight GTPase, comprises MxA and MxB in humans and of Mx1 and Mx2 in mice. ${ }^{79}$ MX family is encoded in human chromosome 21, which is synergic to mouse chromosome $16 .^{80,81} \mathrm{MxA}$ is induced selectively by type I IFNs and its expression requires STAT 1 signaling. ${ }^{82}$ As a result, MxA protein is used as a surrogate marker for type I IFN activity in various experimental and clinical settings. ${ }^{83}$
Mx protein (Mx1) confers resistance to orthomyxoviruses and inhibits an influenza virus in fishes, while (Mx2) inhibits rhabdoviruses and bunya viruses. ${ }^{84}$ The role of $\mathrm{Mx}$ as a predictive marker of antiproliferative effect of IFN- $\alpha$ in melanoma has been studied, ${ }^{85,86}$ also with conflicting results.

Yurkovetsky et al tried to evaluate specific predictive markers of clinical outcome and of IFN $\alpha-2 b$ response in patients with high risk melanoma. ${ }^{87}$ Differences in serum concentrations in 29 cytokines, angiogenic and growth factors in melanoma patients before and after high dose IFN $\alpha-2 b$ therapy and in healthy control groups were analysed. ${ }^{87}$ A statistically significant increase in 15 proteins was observed in melanoma patients comparing to healthy individuals. IFN- $\alpha$ therapy decreased levels of angiogenic and growth factors (Vascular Endothelial Growth Factor VEGF, Epidermal Growth Factor EGF, Hepatocyte Growth Factor HGF), as it was noticed three months after the induction of therapy. However this did not seem to correlate with changes in recurrence free survival (RFS) among this population. It has also been shown that pre-treatment levels of pro-inflammatory cytokines (IL-1a, IL-1b, IL-6, Tumor Necrosis Factor TNFa and Macrophage Inflammatory Protein MIP-1a, MIP-1b) were higher in patients treated with IFN who had a RFS longer than 5 years compared to those with shorter RFS.

Furthermore Critchley-Thorne et $\mathrm{al}^{88}$ studied defects in T cell signaling (IFN signaling) in advanced melanoma patients, likely arising from their impaired response to IFN therapy. The reduced responses to IFNs could be involved in the susceptibility of lymphocytes to spontaneous apoptosis in the cancer state, which is critical of tumor immune dysfunction. These effects were normalized in vitro by exposure to high dose IFN- $\alpha$ Finally it has recently been demonstrated that silencing the suppressor of cytokine signaling (SOCS) proteins on tumor cells, results in enhancement of the anti- proliferative effect of IFN- $\alpha$ and IFN- $\gamma .{ }^{89}$ SOCS proteins are negative regulators of IFN-signaling. ${ }^{90}$ It has been shown that increased levels of these proteins render cells resistant to IFN- $\alpha$ therapy. ${ }^{91}$

Further investigations are required to identify the mechanisms of responsiveness to IFN therapy and to understand the possible mechanisms of resistance. Establishment of response markers would be helpful for the identification of patients who would be more likely benefited from IFN- $\alpha$ therapy.

\section{IFN-induced autoimmunity}

The presence of autoantibodies or other clinical manifestations of autoimmunity after IFN treatment was shown to be associated with a prolongation in relapse-free survival. ${ }^{92}$ 
Gogas et $\mathrm{ll}^{92}$ investigated the appearance of auto-antibodies or other clinical manifestation of autoimmunity in a group of 200 patients in a sub-study of a larger randomized trial. ${ }^{92}$ Patients were enrolled in two groups: in the first they received IFN $\alpha-2 b 15 \mathrm{MIU} / \mathrm{m}^{2}$ iv daily 5 days per week for 4 weeks while in the other they received the same induction dose followed by sc injections of 10 MIU IFN $\alpha-2 b$ thrice weekly for an additional 48 weeks.

Induction of autoantibodies or clinical manifestations of autoimmunity were detected in $52(26 \%)$ patients treated with IFN $\alpha-2 b$. Clinical manifestations of autoimmunity were more frequently detected in the group of patients that received treatment for 1 year. Antithyroid autoantibodies were most frequently observed ( $22 \%$ of the patients), while antinuclear antibodies were observed in $6 \%$ of the studying patients. Vitiligo was reported in $6 \%$ of the patients.

Detection of autoantibodies was associated with statistically significant improvement in relapse-free survival and overall survival (OS). Median relapse-free survival was
16 months among patients without autoimmunity (108 out of 148 ) and was not reached among patients with autoimmunity ( 7 out of 52 had a relapse). Median relapse-free survival in patients without autoimmunity was 16 months (range 0.3-74.3), whereas it was not reached during follow up in patients with autoimmunity (range 3.5-84.7 months) ${ }^{92}$

Nevertheless the role of autoimmunity, including vitiligo-like depigmentation, in patients with melanoma is not observed regularly as it occurs spontaneously or during chemotherapy. Spontaneous vitiligo was considered a favorable prognostic factor even before the advent of treatment with IL-2. ${ }^{93}$ As an example we present a patient with stage IV melanoma that developed vitiligo-like depigmentation during treatment with dacarbazine (DTIC) and pegylated IFN in the University Hospital of Zurich associated with lasting complete remission (see Figure 2). We emphasize that the pattern of pigment loss is not identical to that of vitiligo (no acral and perioral involvement) and therefore should be coined vitiligo-coined depigmentation.

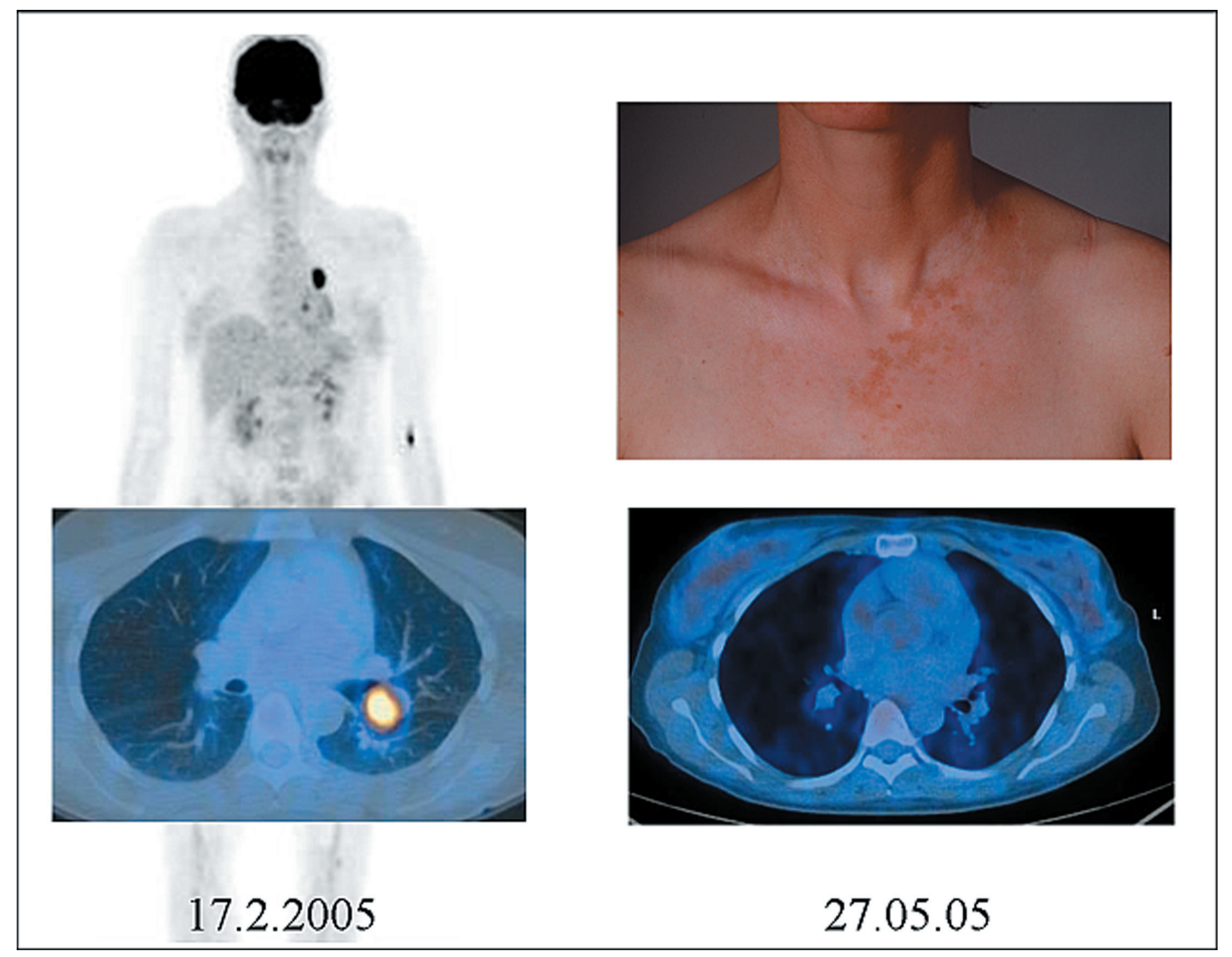

Figure 2 Complete remission associated with vitiligo-like depigmentation after therapy with dacarbazine and PegIFN- $\alpha$. 


\section{Pegylation}

The need for a substance with broader therapeutic effect and more convenient pharmacokinetic profile with less toxicity than conventional IFN led to pegylation of IFN- $\alpha$.

The term pegylation describes the conjugation of a molecule with polyethylene-glycol (Peg), which is used to alter the physical and chemical profile of the molecule.

Pegylation increases the stability and solubility of the drug, prolongs its activity, delays its clearance and reduces protein's immunogenicity. As a result the administration frequency can be reduced; the pegylated form is injected once weekly, rather than 3 times per week for conventional IFN- $\alpha$.

The FDA recently approved two PegIFN- $\alpha$ preparations for the treatment of chronic hepatitis (PegIFN $\alpha-2 b$ was approved in January 2001 while PegIFN $\alpha-2 \alpha$ was approved in October 2002). Unfortunately, PegIFNs are not yet officially approved for the treatment of melanoma.

\section{PegIFN $\alpha-2 b$ (Peg-Intron)}

PegIFN $\alpha-2 b$ presents as a derivate of recombinant IFN $\alpha-2 b$ conjugated with PEG. ${ }^{94}$ The molecular weight of the PEGmoiety is $12 \mathrm{kDa}$ and it is attached to a linkage to histidine-34 on IFN $\alpha-2 b .{ }^{95}$ The average molecular weight of PegIFN $\alpha-2 b$ is $31 \mathrm{kDa} .{ }^{96}$

After sc administration of a single dose of PegIFNo-2b, mean absorption half-life was 4.6 hours. ${ }^{96}$ Glue et al studied the pharmacokinetic profile of several dosages of PegIFNo-2b in patients with chronic hepatitis. Mean elimination half-life at first week after administration of different dose schedules of PegIFN $\alpha-2 \mathrm{~b}(0.35 \mu \mathrm{g} / \mathrm{kg}, 0.7 \mu \mathrm{g} / \mathrm{kg}, 1 \mu \mathrm{g} / \mathrm{kg} 1.4 \mu \mathrm{g} / \mathrm{kg})$ varied from 40 to 58 hours in these patients. The mean peak serum concentrations $\left(\mathrm{C}_{\max }\right)$ in patients receiving the same dosage schedules occurred between 22 and 29 hours at week 1 and between 22 and 19 hours at week 4 after dosing. ${ }^{97}$ This actually means that dose or duration of therapy did not cause much difference to absorption. An increase in bioavailability of Peg-Intron is described after multiple dosing. ${ }^{96}$ Time to steady state is reached by week 4 .

Comparison of pharmacokinetics data in a randomized study with 1219 patients with chronic hepatits-C infection demonstrated no differences in efficacy between patients treated with PegIFN $\alpha-2 b$ in the dose of $0.5 \mu \mathrm{g} / \mathrm{kg}$ once weekly and those treated with sc injections of 3 MIU IFN $\alpha-2 b$ thrice weekly. Patients were treated for 48 weeks and were followed up for an additional period of 24 weeks. Moreover this study showed that efficacy of the combined virologic and biochemical response was increased with an increase in the dose of PegIFN $\alpha-2 b$ compared with conventional IFN. ${ }^{98}$

\section{PegIFN $\alpha-2 \alpha$ (Pegasys $\left.^{\circledR}\right)$}

PegIFN $\alpha-2 \alpha$ is recombinant IFN $\alpha-2 \alpha$ conjugated with a $40 \mathrm{kDa}-$ branched Peg moiety and consists of major isomers. ${ }^{94}$ It is linked to the recombinant IFN via a stable amine to lysine bond. ${ }^{99}$ PegIFN $\alpha-2 \alpha$ has an approximate molecular weight of $60,000 \mathrm{Da}^{99}$

A dose of $180 \mu \mathrm{g}$ of PegIFN $\alpha-2 \alpha$ in healthy volunteers produced $\mathrm{C}_{\max }$ of $14.2 \mu \mathrm{g} / \mathrm{L}$, which was reached in a mean time $\left(\mathrm{T}_{\max }\right.$ ) of 78 hours. ${ }^{100}$ PegIFN $\alpha-2 \alpha$ is cleared both by the liver and the kidney in contrast to PegIFN $\alpha-2 b$ which is cleared by the kidney. The elimination half-life is at about 65 hours. ${ }^{99}$

$\mathrm{C}_{\text {max }}$ and area under the curve (AUC) increased in a nonlinear dose-related manner after administration of different doses of Pegasys ranging from 90 to $270 \mu \mathrm{g} .{ }^{99}$ Maximal serum concentrations occur between 72 and 96 hours. ${ }^{99}$ Steady state serum levels are reached within 5 and 8 weeks of once-weekly dosing. ${ }^{99}$

Drugs with a large volume of distribution require adjustment of a dose according to the prevailing body weight. As a result the $12 \mathrm{kD} \mathrm{PegIFN} \alpha-2 \mathrm{~b}$ is dosed on a weight-basis, whereas the $40 \mathrm{kD}$ Peg IFN $\alpha-2 \alpha$ is given as a flat dose.

Half-life, mean peak concentration time and clearing of conventional IFN and of PegIFN $\alpha-2 b$ and PegIFN $\alpha-2 \alpha$ are compared in Table 1.

\section{Efficacy of PegIFN PegIFN in the adjuvant setting}

The most important factor determining survival in melanoma patients is disease stage. Measurement of tumor thickness with Breslow index and ulceration are used to determine the

Table I Pharmacology of conventional IFN and two pegylated IFN preparations

\begin{tabular}{llll}
\hline & Conventional IFN & I2 kD PegIFN & 40 kD PegIFN \\
\hline Volume of distribution (L) & $25-30$ & $20-40$ & 8 \\
Half-life (h) & $3-8$ & 54 & 65 \\
Time to serum peak (h) & $7-12$ & 20 & 80 \\
Clearing & Renal & Renal & Hepatic and renal \\
\hline
\end{tabular}


prognosis of the primary tumor in stage I and II melanoma patients. ${ }^{101}$ For stage III melanoma patients four major criteria are used to determine outcome: number of metastatic lymph nodes, tumor burden (microscopic or macroscopic), the presence or absence of ulceration of the primary tumor, and the presence or absence of in transit or satellite metastases. ${ }^{101}$

Five-year survival for tumors with a thick Breslow index without involvement of lymph nodes ranges between $27 \%$ and $70 \%$, decreasing to $10 \%$ to $19 \%$ in patients with positive lymph nodes. ${ }^{101}$ One-year survival in patients with distant metastases is $41 \%$ to $59 \%{ }^{101}$ while 10 -year survival rate is $30 \%$ in patients with loco regional metastases in lymph nodes and less than $5 \%$ in those with distant metastases. ${ }^{102}$

With these features in mind, effective, adjuvant, postsurgical treatment following surgical interventions is urgently needed. Adjuvant chemotherapy and irradiation therapy failed to improve survival. Immunotherapy offers at least some promise.

A number of prospective randomized trials have been performed using adjuvant treatment with IFN in patients with cutaneous melanoma. Treatment with low, intermediate and high doses of IFN- $\alpha$ after resection of primary tumor has improved RFS, but without confirmed significant effects on OS. ${ }^{103-105}$

The first trial that showed a positive effect on OS was ECOG 1684. ${ }^{106} 287$ patients were enrolled to receive a high dose of IFN- $\alpha$ for 1 year versus observation. Twenty-five percent of the patients had to be withdrawn due to severe adverse effects. Five-year disease-free survival (DFS) was $37 \%$ versus $26 \%$ and OS was $46 \%$ versus $37 \%$. $^{106}$ On this basis, high-dose adjuvant IFN- $\alpha$ won FDA approval. A metaanalysis of several high dose IFN trials showed no statistically significant effect on OS. ${ }^{104}$ It was then proposed that IFN might exert its best effect in long-term therapy. ${ }^{105}$ Clarification of the role of high dose IFN would need a large prospective trial comparing it with long-term low dose IFN therapy.

Since PegIFN- $\alpha$ is suitable for long-term therapy, the European Organisation for Research and treatment of Cancer (EORTC) has designed a large prospective randomized trial to investigate the potent positive effect of PegIFN $\alpha-2 b$ in the adjuvant setting in patients with stage III melanoma. The largest trial ever conducted with PegIFN (EORTC 18991 study) was recently published. ${ }^{107} 1256$ patients from 99 centers in 17 countries with resected stage III melanoma were randomized to receive observation or PegIFN- $\alpha{ }^{107}$ Randomization was stratified for microscopic (N1) versus macroscopic (N2) nodal involvement, number of positive nodes, ulceration and tumor thickness. RFS (primary endpoint), distant-metastases-free survival (DMFS) and OS were analyzed for the intent-to-treat population.

The IFN group received an induction IFN dose of weekly dose of $6 \mu \mathrm{g} / \mathrm{kg}$ for the first 8 weeks and then the dose was reduced to $3 \mu \mathrm{g} / \mathrm{kg}$ per week for 5 years. ${ }^{107}$

At 3.8 years of median follow up, RFS was significantly reduced by $18 \%$ in the PegIFNo-2b arm compared with observation; the 4-year RFS rate was $45.6 \%$ versus $38.9 \%$. DMFS was improved but nonsignificantly ( $p=0.11)$. OS was unchanged in the two groups. In stage III-N1a (micro metastases detected in the sentinel node) both RFS (hazard ratio [HR] $0.72,57.7 \%$ versus $45.4 \%, \mathrm{p}=0.01$ ) and DMFS (HR $0.73,60.5 \%$ versus $52.6 \%, \mathrm{p}=0.01$ ) were prolonged in the PegIFN $\alpha-2 b$ arm, whereas in stage III-N1b (macroscopic metastases) there was no benefit. ${ }^{107}$

This trial showed that a prolonged adjuvant treatment with IFN- $\alpha$ improved the RFS period and DMFS in a subgroup of patients with low tumor burden. According to these results, further search for predictive clinical or biological markers that can identify patients who are more likely to benefit from IFN treatment is encouraged. ${ }^{107}$

Safety and efficacy of adjuvant treatment with PegIFN $\alpha-2 \alpha$ $100 \mu \mathrm{g}$ sc weekly for 36 months versus conventional $3 \mathrm{MIU}$ IFN $\alpha-2 \alpha$ thrice weekly for 18 months is investigated in another European, multicenter, prospective trial performed by the Dermatologic Cooperative Oncology Group (EADO). 880 patients with melanoma stage IIA-IIIB are randomized to receive adjuvant treatment after surgical excision. Inclusion criteria were tumor thickness $>1.5 \mathrm{~mm}$ and absence of regional nodal macro-metastases as assessed either by clinical examination or if, sentinel lymph node dissection (SLNB) or elective node dissection (ELND) are performed, by the absence of macroscopic evidence of disease. Patients with evidence of nodal macro-metastasis by SNLB or ELND are eligible. The primary endpoint of the study is 5-year DFS. The results are pending.

Another randomized European trial is investigating PegIFN $\alpha-2 \alpha$ in a dose of $180 \mu \mathrm{g}$ per week versus observation.

\section{PegIFN in palliative disease (stage IV melanoma)}

As noted to above, stage IV malignant melanoma remains a rapidly fatal disease despite treatment. ${ }^{102}$ Surgical excision, systemic chemotherapy, irradiation, immunotherapy or combinations of these are offered to patients without any proven evidence for any effect on survival. Therefore participation in clinical trials is recommended. 


\section{PegIFN as monotherapy in stage IV melanoma}

The use of PegIFN as monotherapy was evaluated in a study reporting a multicenter, randomized-dose comparison phase II trial. ${ }^{108}$ This trial evaluated the efficacy of PegIFN monotherapy in patients with stage IV metastatic melanoma. 150 patients were randomized to receive PegIFN in three different dose-schedules. One group received $180 \mu \mathrm{g}$ once a week; other groups received $360 \mu \mathrm{g}$ or $450 \mu \mathrm{g}$ weekly. The treatment phase was 24 weeks, followed by an 8 -week follow up time. Patients with previous chemotherapy or immunotherapy with IL-2 for stage IV melanoma were excluded. Approximately $20 \%$ of the patients had previously received IFN as adjuvant therapy. ${ }^{108}$ Tumor responses were confirmed by an independent radiology review board. The overall response rate (complete or partial response) was $6 \%, 8 \%$ and $12 \%$ for the three groups, respectively. The difference between the dose groups was not statistically significant. In addition, there was a tendency that low-dose treated patients presented a higher tumor burden. There was also no significant difference between stable and progressive disease among three groups. ${ }^{108}$

Unfortunately this trial does not clarify whether there is a true dose-response relationship with PegIFN in patients with metastatic melanoma due to the small number of the patients recruited in this study. The overall response rate in this trial is very similar to the response rate in a comparable patient population treated with DTIC monochemotherapy. ${ }^{109,110}$ It is challenging to argue that the targeted population includes a minority of patients who are able to respond to a therapeutic intervention, independent of its nature.

\section{PegIFN in combination with chemotherapy}

The combination of PegIFN and chemotherapy has been evaluated in different types of cancers. ${ }^{111,112}$ Several studies have been performed to evaluate the efficacy of combined chemotherapy and immunotherapy in patients with melanoma.

A randomized trial performed by the German Dermatologic Cooperative Oncology group (DECOG) investigated temozolomide (TMZ) alone in a daily dose of $200 \mathrm{mg} / \mathrm{m}^{2}$; (day $1-5$ every 28 days) or in combination with sc IFN- $\alpha$ $\left(5 \mathrm{MIU} / \mathrm{m}^{2}\right.$; day $1,3,5$, every week). ${ }^{113} 282$ patients were eligible for intent-to-treat analysis, 271 patients were treated per protocol. In the TMZ plus IFN- $\alpha$ arm, 33 out of 137 patients $(24.1 \%)$ responded to therapy (partial or complete response) whereas in monotherapy arm in 18 of 134 patients $(13.4 \%)$ a response was evident. Thus the response rate was significant higher in the combination arm $(p=0.036)$. Median survival time was 8.4 months for patients treated with TMZ and 9.7 months for those treated with the combination $(p=0.16)$. Dose modifications and interval prolongations due to hematologic toxicity were significantly more frequent in the combination group $(p=0.001) .{ }^{113}$ These results were indicators for further investigation.

Hwu et al enrolled 35 patients with stage IV melanoma to receive $0.5 \mu \mathrm{g} / \mathrm{kg}$ weekly PegIFN $\alpha$-2b plus TMZ $75 \mathrm{mg} / \mathrm{m}^{2}$ daily for 6 days per week with a 2-week break between the cycles. ${ }^{114}$ Patients with brain metastases, pregnant or lactating patients or patients with evidence of other tumor except nonmelanoma skin or in situ cervical cancer were excluded. Median number of metastatic sites was 3 and the most common sites of metastasis were soft tissue, lymph nodes and lungs, indicating a selection of patients with a relatively favorable prognosis. No patient had received previous chemotherapy. Thirty-one percent of the patients experienced objective response (complete and partial) while $6 \%$ had stable disease (SD) which is a surprising ratio. Sixty-three percent of the patients had progressive disease. At the time of the last follow up 27 out of 35 patients had died of their disease. The median survival for the responders (both complete response [CR] and partial response [PR]) was 20.2 months and the median survival time for nonresponders was 6.9 months. ${ }^{114}$ This study reported a very high response rate which was not confirmed by independent radiology assessment. The survival reported is longer than with dacarbazine or TMZ alone ${ }^{115}$ but again the results need confirmation in a randomized trial.

No grade IV hematological adverse effects (AEs) were experienced in the study. Other grade IV adverse effects were central nervous system hemorrhage and thrombosis/ pulmonary embolism reported in one case (3\%). This seemed to be neither PegIFN dose-related nor disease-dependent (hemorrhagic stroke in the absence of thrombocytopenia or clinical evidence of brain metastasis).

The efficacy of PegIFN $\alpha-2 b$ combined with monochemotherapy was investigated in another study performed by Spieth et al. ${ }^{116}$ The study was designed based on previously published results from DECOG using combination of immunotherapy and chemotherapy. ${ }^{113} 124$ patients with metastatic melanoma were included in the study. The patients received oral TMZ $200 \mathrm{mg} / \mathrm{m}^{2}$ for 5 days every 28 days. In addition sc injections of $100 \mu \mathrm{g}$ PegIFN $\alpha-2 b$ were administered once a week. ${ }^{116}$ Patients with brain metastases were excluded as 
were patients with severe cardiac, pulmonary, psychiatric or metabolic diseases. No patient had received prior systemic chemotherapy. In all patients, 18.1\% showed complete or partial response, $25 \%$ achieved stable disease, while in $56.9 \%$ of the patients the disease was progressive. ${ }^{116}$ Median overall survival (MOS) in responders was 15.2 months and in nonresponders was 8.6 months. Fifty out of 116 patients had an adjustment in the treatment due to adverse effects. ${ }^{116}$ Grade III and grade IV toxicities included leukopenia $(23.3 \%)$ and thrombocytopenia (41.4\%), which is more than observed with TMZ alone. One patient was diagnosed with sarcoidosis shortly after initiation of treatment.

Twenty-eight patients with stage IV malignant melanoma without brain metastases were enrolled in a multicenter phase II study. ${ }^{117}$ Patients were treated with $850 \mathrm{mg} / \mathrm{m}^{2}$ DTIC every 3 weeks combined with $180 \mu$ g PegIFN $\alpha-2 \alpha$ weekly. Only $50 \%$ of the patients participating in the study had received previous adjuvant therapy with IFN- $\alpha$. This study was initiated to evaluate the efficacy and tolerability of the combination. Primary endpoint was objective response (OR).

Two patients (8\%) achieved CR which lasted for more than 480 days and for 746 days respectively. Four patients (16\%) had a PR and another patient developed SD, which means that $24 \%$ of the patients achieved PR or CR. Median progression-free survival was 56 days, median duration of response was 236 days and OS time was 403 days. ${ }^{117}$ Of interest is the fact that 6 out of 7 patients who showed CR or PR or developed SD had not received IFN adjuvant treatment in the past or progressed to stage IV melanoma during IFN treatment.

One patient had to discontinue the treatment due to serious AE (dizziness). The patient discontinued the treatment after showing complete response of her lung metastases.

This combination was well tolerated. Because of the design, the impact on survival cannot be assessed. The long-term remission observed in IFN-naïve patients suggests that combination of chemotherapy with IFN might be especially promising in this population.

Vaishampayan et al aimed to evaluate the efficacy of PegIFN $\alpha-2 b$ combined with thalidomide in patients with stage IV metastatic melanoma. Eighteen patients were enrolled to receive $0.5 \mu \mathrm{g} / \mathrm{kg}$ sc daily plus 250 mg thalidomide orally. ${ }^{118}$ Nine out of 18 patients had received previous adjuvant treatment, while 16 out of 18 patients had also received previous chemotherapy. ${ }^{118}$ No objective responses were noted; 3 patients demonstrated disease stabilization for a rate of $3 / 18=17 \%(90 \%$ confidence interval [CI] 0.06-0.35). ${ }^{118}$ The stable disease durations were 4, 5 and 15 months. Median survival was 7.2 months, with $90 \%$ CI, 4.1-13.6 months. ${ }^{118}$ The 6-month and 1-year OS rates were $58 \%$ and $35 \%$, respectively. Grade IV toxicity was hematologic toxicity (anemia and thrombocytopenia) which was experienced in 3 of 18 (16.6\%) patients. The combination was well tolerated, though without clinical efficacy.

\section{Side effects of PegIFNs}

IFN- $\alpha$ therapy is associated with a wide spectrum of side effects that present in various severities depending on dose and individual susceptibility. Unfortunately, there are no clinical or laboratory studies predicting individual tolerability. The FDA defines a serious AE to be life threatening or to cause death, or initial or prolonged hospitalization, or when one AE causes significant, persistent, or permanent disability, impairment, or disruption in the patient's body structure, physical activities, or quality of life. ${ }^{119}$ An AE is also considered serious when it requires intervention to prevent permanent damage. ${ }^{19}$

Initially, the patients who are candidates for IFN therapy need detailed information about the nature of the drug. Understanding IFN as a biologic medication and not another cytostatic drug contributes to a better acceptance of the most prominent flu-like side symptoms. It is also helpful to encourage variations in the treatment schedule that interfere as little as possible with the daily activity of the individual.

Several interventions to alleviate the constitutional side effects such as dose decrement or cessation of treatment interruptions are necessary. Premedication with acetaminophen, ibuprofen or other non-steroidal anti-inflammatory drugs (NSAIDs) and/or antiemetics is believed to reduce the severity of flu-like symptoms. ${ }^{120}$ IFN administration at bedtime can also help. ${ }^{121}$ Patients are also advised to avoid hepatotoxic agents and large quantities of alcohol while on treatment with IFN. Regular hematological and biochemical tests (including thyroid antibodies) need to be drawn at baseline, monthly for the first 3 months and afterwards every 3 months when patients are treated with PegIFN- $\alpha .^{96,99}$

\section{Side effects of PegIFN $\alpha-2 b$}

In Table 2 we compare the most commonly reported adverse effects related to IFN $\alpha-2 b$ and PegIFN $\alpha-2 b$ therapy.

There are no significant differences between the incidence of AEs experienced by hepatitis patients comparing low doses of PegIFN $\alpha-2 b(1 \mu \mathrm{g} / \mathrm{kg})$ and conventional IFN $\alpha-2 b$ at a dose of $3 \mathrm{MIU}$ (see Table 2). 


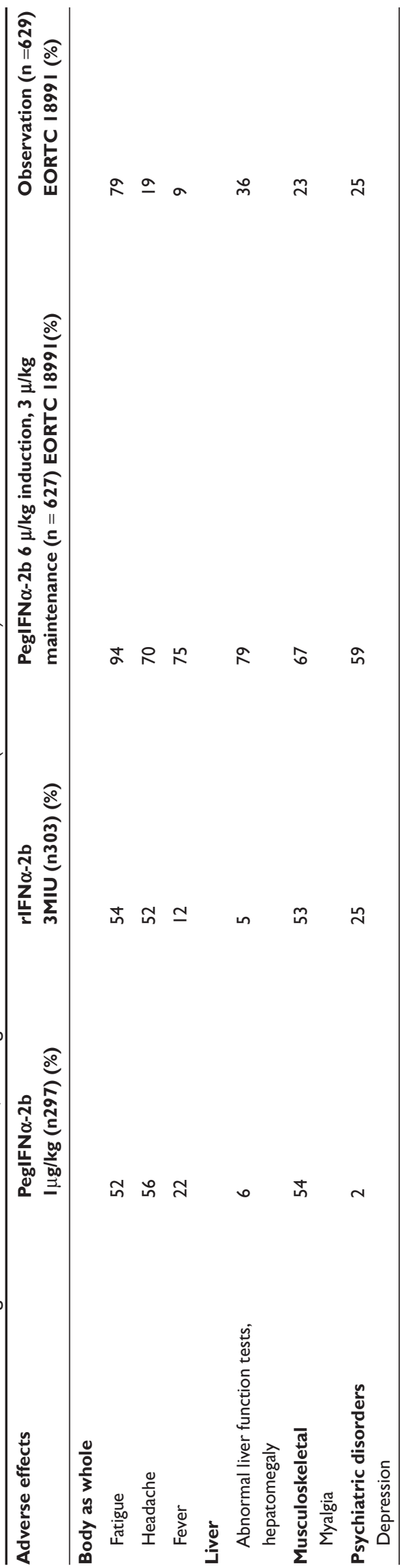

In the population of melanoma patients treated in the EORTC 18991 study, $31 \%$ treated with PegIFN $\alpha-2 b$ discontinued treatment due to AEs. ${ }^{107}$ Flu-like symptoms and depression were more severe in the PegIFN group compared to observation (see Table 2). Grade I-IV AEs most often associated with drug discontinuation were fatigue (25\%), depression (16\%), anorexia (15\%), abnormal liver function tests $(13 \%)$, myalgias $(13 \%)$, headache $(12 \%)$, nausea $(12 \%)$ and pyrexia (11\%). ${ }^{107}$ The incidence of these symptoms was higher early in treatment and did not seem to increase with longer treatment duration. ${ }^{107}$

\section{Side effects of PegIFN $\alpha-2 \alpha$}

In Table 3 we compare the most commonly reported AEs related to IFN $\alpha-2 \alpha$ and PegIFN $\alpha-2 \alpha$ therapy.

As with PegIFN $\alpha-2 b$ and IFN $\alpha-2 b$, there are no significant differences in incidence of AEs comparing IFN $\alpha-2 \alpha$ and PegIFN $\alpha-2 b$ at the doses of 3 MIU and $180 \mu \mathrm{g}$ respectively.

As it can be seen from Table 3 in the study performed by Dummer et al in melanoma patients, there were also no meaningful differences in AEs recorded for the three doses of PegIFN. Reductions or withholding of doses due to AEs or laboratory abnormalities were documented in $23 \%$ $(\mathrm{n}=11), 51 \%(\mathrm{n}=27)$ and $41 \%(\mathrm{n}=20)$ of patients treated with PegIFN $\alpha-2 \alpha$ at doses of 180,360 and $450 \mu \mathrm{g}$, respectively. ${ }^{108}$ In all dose groups, most dose adjustments occurred in the first 3 months.

According to this trial, fatigue and flu-like symptoms were the most frequently reported AEs, with $14 \%$ of patients in the $450 \mu \mathrm{g}$ group reporting severe fatigue. Ninety-six percent of patients in the $180 \mu \mathrm{g}$ group and $100 \%$ in the $360 \mu \mathrm{g}$ and $450 \mu \mathrm{g}$ groups experienced at least one $\mathrm{AE}$ but $88 \%$ of these were mild or moderate. ${ }^{108}$

There was a clear difference in the AE-based discontinuation rate between the $180 \mu \mathrm{g}$ weekly versus the $360 \mu \mathrm{g}$ group. However, there was no obvious difference between the $360 \mu \mathrm{g}$ and $450 \mu \mathrm{g} /$ weekly groups. ${ }^{108}$

Other rare toxicities related to PegIFN therapy include retinopathy, retinal hemorrhage, optic neuritis and papilledema. Bone marrow toxicity, alopecia and injection side reactions are uncommon AEs. ${ }^{96,99}$ PegIFN treatment is also related to exacerbation or development of autoimmune diseases such as thyroiditis, adrenal dysfunction, Raynaud phenomenon, psoriasis, autoimmune hepatitis, rheumatoid arthritis and lupus erythematosus. Sarcoidosis, interstitial lung disease, StevensJohnson Syndrome, erythema multiform and Lyell Syndrome are very rare AEs related to PegIFN treatment. ${ }^{122}$ 
Table 3 Side effects of PegIFN $\alpha-2 \alpha$ and rIFN $\alpha-2 \alpha$ (occurring in $>5 \%$ of the patients) and different doses of PegIFN $\alpha-2 \alpha$ alone (occurring in more than $15 \%$ of patients ${ }^{99,108}$

\begin{tabular}{|c|c|c|c|c|c|}
\hline Adverse effects & $\begin{array}{l}\text { PegIFN } \alpha-2 \alpha \\
\text { I } 80 \mu g(n=559)(\%)\end{array}$ & $\begin{array}{l}\operatorname{rIFN} \alpha-2 \alpha \\
3 \operatorname{MIU}(n=554)(\%)\end{array}$ & $\begin{array}{l}\text { PegIFN } \alpha-2 \alpha \\
I 80 \mu g(n=48)(\%)\end{array}$ & $\begin{array}{l}\text { PegalFN } \alpha-2 \alpha \\
360 \mu \mathrm{g}(\mathrm{n}=53)(\%)\end{array}$ & $\begin{array}{l}\text { PegIFN } \alpha-2 \alpha \\
450 \mu g(n=49)(\%)\end{array}$ \\
\hline \multicolumn{6}{|l|}{ Body as whole } \\
\hline Fatigue & 56 & 57 & 52 & 57 & 59 \\
\hline Headache & 54 & 58 & 19 & 26 & 35 \\
\hline Rigors & 35 & 44 & 29 & 32 & 20 \\
\hline Fever & 37 & 41 & 44 & 43 & 49 \\
\hline \multicolumn{6}{|c|}{ Central nervous system } \\
\hline Dizziness & 16 & 12 & 6 & 9 & 20 \\
\hline \multicolumn{6}{|l|}{ Gastrointestinal } \\
\hline Nausea & 24 & 33 & 42 & 34 & 39 \\
\hline Anorexia & 17 & 17 & 21 & 21 & 41 \\
\hline Diarrhea & 16 & 16 & 21 & 19 & 18 \\
\hline \multicolumn{6}{|l|}{ Musculoskeletal } \\
\hline Myalgia & 37 & 38 & 19 & 19 & 29 \\
\hline Arthralgia & 28 & 29 & 6 & 17 & 22 \\
\hline Musculoskeletal pain & 9 & 10 & 12 & 17 & 20 \\
\hline \multicolumn{6}{|l|}{ Respiratory } \\
\hline Dyspnea & 4 & 2 & 10 & 19 & 12 \\
\hline Coughing & 4 & 3 & 19 & 8 & 20 \\
\hline
\end{tabular}

Note: All values are \%.

\section{Summary and conclusions}

PegIFNs have been successfully introduced into melanoma therapy. Their pharmacologic profile allows a comfortable once weekly injection schedules. In the adjuvant setting PegIFN $\alpha-2 b$ is the preferred medication for long-term therapy that increases distant metastases-free survival in patients with microscopic node involvement. Especially young patients with no significant co-morbidities are candidates for this approach. Side effects of PegIFNs are substantial. Therefore, there is a strong need for a detailed discussion of the pros and cons with the patient before therapy. The most common adverse effects include constitutional, neuropsychiatric, hematologic and hepatic toxicity. Careful monitoring during treatment is necessary. Side effects are dose-dependent and they affect patient quality of life. An ongoing dialogue must occur between the patient and physician to ensure that all aspects of toxicity related to PegIFN are anticipated and treated. Autoimmunity phenomena induced by IFN treatment may be important surrogate markers for successful antitumor effect. However additional predictive markers are necessary to identify the melanoma population who will benefit most from this immunotherapy.

Large multicenter trials in specialized centers are encouraged to address this issue by the collection of biological samples in large bio-banks.

\section{Disclosures}

RD has served on the advisory boards for Roche and Schering-Plough.

\section{References}

1. Isaacs A, Lindenmann J. Virus Interference. I The interferon. Proc $R$ Soc. London Ser B. 1957; 147:258.

2. Kerr IM, Stark GR. The antiviral effects of the interferons and their inhibition. J Interferon Res. 1992;12:237-240.

3. Samuel CE: Antiviral actions of interferons. Clin Microbiol Rev. 2001;14:778-809.

4. Sen GC, Lengyel P. The interferon system. A bird's eye view of its biochemistry. J Biol Chem. 1992;267:5017-5020.

5. Nathan C. Interferon and inflammation. In: Gallin JI, Goldstein IM, Schnyder R, editors. Inflammation: basic principles and clinical correlates. New York: Raven Press; 1992. p. 265-290.

6. Beattie E, Tartaglia J, Paoletti. E. Vaccinia virus-encoded elF-2a homolog abbrogates the anitiviral effect of interferon. Virology. 1991;183:419-422.

7. Bandyopadhyay S, Perussia B, Trinchieri G, et al. Requirement for HLA-DR+ accessory cells in natural killing of cytomegalovirus-infected fibroblasts. $J$ Exp Med. 1986;164:180-195.

8. Siegal FP, Kadowaki N, Shodell M, et al. The nature of the principal type 1 interferon-producing cells in human blood. Science. 1999;284:1835-1837.

9. Cella M, Jarrossay D, Facchetti F, et al. Plasmacytoid monocytes migrate to inflamed lymph nodes and produce large amounts of type I interferon. Nat Med. 1999;5:919-923.

10. Colonna M, Trinchieri G, Liu YJ. Plasmacytoid dendritic cells in immunity. Nat Immunol. 2004;5:1219-1226.

11. McKenna K, Beignon AS, Bhardwaj N. Plasmacytoid dendritic cells: linking innate and adaptive immunity. $J$ Virol. 2005;79:17-27. 
12. Iwasaki A, Medzhitov R. Toll-like receptor control of the adaptive immune responses. Nat Immunol. 2004;5:987-995.

13. Bell D, Chomarat $\mathrm{P}$, Broyles $\mathrm{D}$, et al. In breast carcinoma tissue, immature dendritic cells reside within the tumor, whereas mature dendritic cells are located in peritumoral areas. J Exp Med. 1999;190:1417-1426.

14. Vermi W, Bonecchi R, Facchetti F, et al. Recruitment of immature plasmacytoid dendritic cells (plasmacytoid monocytes) and myeloid dendritic cells in primary cutaneous melanomas. J Pathol. 2003;200:255-268

15. Liu C, Lou Y, Lizee G, et al. Plasmacytoid dendritic cells induce NK cell-dependent, tumor antigen-specific T cell cross-priming and tumor regression in mice. $J$ Clin Invest. 2008;118:1165-1175.

16. Pestka S, Langer JA, Zoon KC, et al. Interferons and their actions. Annu Rev Biochem. 1987;56:727-777.

17. Kaplan DH, Shankaran V, Dighe AS, et al. Demonstration of an interferon gamma-dependent tumor surveillance system in immunocompetent mice. Proc Natl Acad Sci U S A. 1998;95:7556-7561.

18. Dunn GP, Bruce AT, Sheehan KC, et al. A critical function for type I interferons in cancer immunoediting. Nat Immunol. 2005;6:722-729.

19. Paredes J, Krown SE. Interferon-alpha therapy in patients with Kaposi's sarcoma and the acquired immunodeficiency syndrome. Int $J$ Immunopharmacol. 1991;(13 Suppl 1):77-81.

20. Baron S, Tyring SK, Fleischmann WR Jr, et al. The interferons. Mechanisms of action and clinical applications. Jama. 1991;266:1375-1383.

21. Borden EC: Interferons in JF Holland, Frei III, JR Bast, DW Kufe, DL. Morton and RR Wechselbaum (eds). Cancer Medicine MD: Wiliams and Wilkins. 1997;1119-1212.

22. Gutterman JU. Cytokine therapeutics: lessons from interferon alpha. Proc Natl Acad Sci U S A. 1994;91:1198-1205.

23. Buzaid AC, Robertone A, Kisala C, et al. Phase II study of interferon alfa-2a, recombinant (Roferon-A) in metastatic renal cell carcinoma. J Clin Oncol. 1987;5:1083-1089.

24. Krown SE. Interferon treatment of renal cell carcinoma. Current status and future prospects. Cancer. 1987;59:647-651.

25. Interferon Nomenclature. Nature. 1980;286:110.

26. Platanias LC. Mechanisms of type-I- and type-II-interferon-mediated signalling. Nat Rev Immunol. 2005;5:375-386.

27. Pestka S. The human interferon-alpha species and hybrid proteins. Semin Oncol. 1997;24:S9-4, S9-17.

28. LaFleur DW, Nardelli B, Tsareva T, et al. Interferon-kappa, a novel type I interferon expressed in human keratinocytes. J Biol Chem. 2001;276:39765-39771.

29. Conklin D, Grant F, Rixon M, et al. Interferon-epsilon. US Patent. 2002;6329175.

30. Kotenko SV, Gallagher G, Baurin VV, et al. IFN-lambdas mediate antiviral protection through a distinct class II cytokine receptor complex. Nat Immunol. 2003;4:69-77.

31. Pestka S, Krause CD, Walter MR. Interferons, interferon-like cytokines, and their receptors. Immunol Rev. 2004;202:8-32.

32. Pestka $\mathrm{S}$. The human interferon alpha species and receptors. Biopolymers. 2000;55:254-287.

33. Weissmann C, Nagata S, Boll W, et al. Structure and expression of human IFN-alpha genes. Philos Trans R Soc Lond B Biol Sci. 1982;299:7-28.

34. Weiss K. Safety profile of interferon-alpha therapy. Semin Oncol. 1998;25:9-13.

35. Goodin DS, Frohman EM, Garmany GP Jr, et al. Disease modifying therapies in multiple sclerosis: report of the Therapeutics and Technology Assessment Subcommittee of the American Academy of Neurology and the MS Council for Clinical Practice Guidelines. Neurology. 2002; $58: 169-178$

36. Weinstock-Guttman B, Jacobs LD. What is new in the treatment of multiple sclerosis? Drugs. 2000;59:401-410.

37. Domanski P, Colamonici OR. The type-I interferon receptor. The long and short of it. Cytokine Growth Factor Rev. 1996;7:143-151.

38. Schindler C, Shuai K, Prezioso VR, et al. Interferon-dependent tyrosine phosphorylation of a latent cytoplasmic transcription factor. Science. 1992;257:809-813.
39. Fu XY, Schindler C, Improta T, et al. The proteins of ISGF-3, the interferon alpha-induced transcriptional activator, define a gene family involved in signal transduction. Proc Natl Acad Sci U S A. 1992;89:7840-7843.

40. Shuai K, Schindler C, Prezioso VR, et al. Activation of transcription by IFN-gamma: tyrosine phosphorylation of a $91-\mathrm{kD}$ DNA binding protein. Science. 1992;258:1808-1812.

41. Chen J, Baig E, Fish NE. Diversity and relatedness among the type I interferons. J Interfon Cytokine Res. 2004;24:687-9-698.

42. Darnell JE, Jr. Kerr IM, Stark GR. Jak-STAT pathways and transcriptional activation in response to IFNs and other extracellular signaling proteins. Science. 1994;264:1415-1421.

43. Ihle JN . The Janus protein tyrosine kinase family and its role in cytokine signaling. Adv Immunol. 1995;60:1-35.

44. Parmar S, Platanias LC. Interferons: mechanisms of action and clinical applications. Curr Opin Oncol. 2003;15:431-439.

45. Horvath CM, Darnell JE Jr. The antiviral state induced by alpha interferon and gamma interferon requires transcriptionally active Stat 1 protein. J Virol. 1996;70:647-650.

46. Darnell JE Jr. STATs and gene regulation. Science 1997;277:1630-1635.

47. Aaronson DS, Horvath CM. A road map for those who don't know JAK-STAT. Science. 2002;296:1653-1655.

48. Meinke A, Barahmand-Pour F, Wohrl S, et al. Activation of different Stat5 isoforms contributes to cell-type-restricted signaling in response to interferons. Mol Cell Biol. 1996;16:6937-6944.

49. Farrar JD, Smith JD, Murphy TL, et al. Recruitment of Stat4 to the human interferon-alpha/beta receptor requires activated Stat2. $J$ Biol Chem. 2000;275:2693-2697.

50. Torpey N, Maher SE, Bothwell AL, et al. Interferon alpha but not interleukin 12 activates STAT4 signaling in human vascular endothelial cells. J Biol Chem. 2004;279:26789-267896.

51. Matikainen S, Sareneva T, Ronni T, et al. Interferon-alpha activates multiple STAT proteins and upregulates proliferation-associated IL-2Ralpha, c-myc, and pim-1 genes in human T cells. Blood. 1999;93:1980-19891.

52. Fasler-Kan E, Pansky A, Wiederkehr M, et al. Interferon-alpha activates signal transducers and activators of transcription 5 and 6 in Daudi cells. Eur J Biochem. 1998;254:514-519.

53. Uddin S, Majchrzak B, Woodson J, et al. Activation of the p38 mitogen-activated protein kinase by type I interferons. J Biol Chem. 1999;274:30127-30131.

54. Goh KC, Haque SJ, Williams BR. p38 MAP kinase is required for STAT1 serine phosphorylation and transcriptional activation induced by interferons. EMBO J. 1999; 18:5601-5608.

55. Li Y, Sassano A, Majchrzak B, et al. Role of p38a Map kinase in type I interferon signaling. J Biol Chem. 2004;279:970-979.

56. Uddin S, Yenush L, Sun XJ, et al. Interferon-alpha engages the insulin receptor substrate-1 to associate with the phosphatidylinositol 3'-kinase. J Biol Chem. 1995;270:15938-15941

57. Ahmad S, Alsayed YM, Druker BJ, et al. The type I interferon receptor mediates tyrosine phosphorylation of the CrkL adaptor protein. J Biol Chem. 1997;272:29991-29994.

58. Roberts RM, Ealy AD, Alexenko AP, et al. Trophoblast interferons. Placenta. 1999;20:259-264.

59. Bazer FW, Spencer TE, Ott TL. Interferon tau: a novel pregnancy recognition signal. Am J Reprod Immunol. 1997;37:412-420.

60. Chen J, Wood W. Interferon PRO655. Genentech. [US 6,300,475] (Patent). 2003;1-37.

61. Ealick SE, Cook WJ, Vijay-Kumar S, et al. Three-dimensional structure of recombinant human interferon-gamma. Science. 1991;252:698-702.

62. Carnaud C, Lee D, Donnars O, et al. Cutting edge: Cross-talk between cells of the innate immune system: NKT cells rapidly activate NK cells. J Immunol. 1999;163:4647-4650.

63. Frucht DM, Fukao T, Bogdan C, et al. IFN-gamma production by antigen-presenting cells: mechanisms emerge. Trends Immunol. 2001;22:556-560. 
64. Flaishon L, Hershkoviz R, Lantner F, et al. Autocrine secretion of interferon gamma negatively regulates homing of immature B cells. J Exp Med. 2000;192:1381-1388.

65. Harris DP, Haynes L, Sayles PC, et al. Reciprocal regulation of polarized cytokine production by effector B and T cells. Nat Immunol. 2000;1:475-482.

66. Perussia B, Kobayashi M, Rossi ME, et al. Immune interferon enhances functional properties of human granulocytes: role of $\mathrm{Fc}$ receptors and effect of lymphotoxin, tumor necrosis factor, and granulocyte-macrophage colony-stimulating factor. J Immunol. 1987;138:765-774.

67. Schroder K, Hertzog PJ, Ravasi T, et al. Interferon-gamma: an overview of signals, mechanisms and functions. J Leukoc Biol. 2004;75:163-189.

68. Bach EA, Aguet M, Schreiber RD. The IFN gamma receptor: a paradigm for cytokine receptor signaling. Anпи Rev Immunol. 1997;15:563-591.

69. Stark GR, Kerr IM, Williams BR, et al. How cells respond to interferons. Аnпu Rev Biochem. 1998;67:227-264.

70. Boehm U, Klamp T, Groot M, et al. Cellular responses to interferongamma. Апnи Rev Immunol. 1997;15:749-795.

71. Dummer R, Cozzio A, Urosevic M. Interferons in cutaneous T-cell Lymphomas. Hematologica Reports. 2006;2(13):71-74.

72. Roferon Drug Information: Roche Laboratories; Nutley, NJ.

73. Cada D, Convington T, et al. Drug Facts and Comparisons. St. Louis Misouri:Facts and Comparisons, Inc. 2000;1571d-1580.

74. Creasey AA, Eppstein DA, Marsh YV, et al. Growth regulation of melanoma cells by interferon and $\left(2^{\prime}-5\right.$ ')oligoadenylate synthetase. Mol Cell Biol. 1983;3:780-786.

75. Buzaid AC, Grimm EA, Ali-Osman F, et al. Mechanism of the anti-tumour effect of biochemotherapy in melanoma: preliminary results. Melanoma Res. 1994;4:327-330.

76. Anderson CM, Buzaid AC, Sussman J, et al. Nitric oxide and neopterin levels and clinical response in stage III melanoma patients receiving concurrent biochemotherapy. Melanoma Res. 1998;8:149-155.

77. Bernengo MG, Quaglino P, Cappello N, et al. Macrophage-mediated immunostimulation modulates therapeutic efficacy of interleukin-2 based chemoimmunotherapy in advanced metastatic melanoma patients. Melanoma Res. 2000;10:55-65.

78. Haller O, Arnheiter H, Lindenmann J, et al. Host gene influences sensitivity to interferon action selectively for influenza virus. Nature. 1980;283:660-662.

79. Sadler AJ, Williams BR. Interferon-inducible antiviral effectors. Nat Rev Immunol. 2008;8:559-568.

80. Aebi M, Fah J, Hurt N, et al. cDNA structures and regulation of two interferon-induced human Mx proteins. Mol Cell Biol. 1989;9:5062-5072.

81. Horisberger MA, McMaster GK, Zeller H, et al. Cloning and sequence analyses of cDNAs for interferon- and virus-induced human $\mathrm{Mx}$ proteins reveal that they contain putative guanine nucleotide-binding sites: functional study of the corresponding gene promoter. $J$ Virol. 1990;64:1171-1181.

82. Holzinger D, Jorns C, Stertz S, et al. Induction of MxA gene expression by influenza A virus requires type I or type III interferon signaling. J Virol. 2007;81:7776-7785.

83. Gilli F, Marnetto F, Caldano M, et al. Biological markers of interferonbeta therapy: comparison among interferon-stimulated genes MxA, TRAIL and XAF-1. Mult Scler. 2006;12:47-57.

84. Haller O, Kochs G. Interferon-induced mx proteins: dynamin-like GTPases with antiviral activity. Traffic. 2002;3:710-7.

85. Jakschies D, Hochkeppel HK, Horisberger MA, et al. Correlation of the antiproliferative effect and the Mx-homologous protein induction by IFN in patients with malignant melanoma. $J$ Invest Dermatol. 1990;95:238S-241S

86. Ralph SJ, Wines BD, Payne MJ, et al. Resistance of melanoma cell lines to interferons correlates with reduction of IFN-induced tyrosine phosphorylation. Induction of the anti-viral state by IFN is prevented by tyrosine kinase inhibitors. J Immunol. 1995;154:2248-2256.
87. Yurkovetsky ZR, Kirkwood JM, Edington HD, et al. Multiplex analysis of serum cytokines in melanoma patients treated with interferonalpha2b. Clin Cancer Res. 2007;13:2422-2428.

88. Critchley-Thorne RJ, Yan N, Nacu S, et al. Down-regulation of the interferon signaling pathway in $\mathrm{T}$ lymphocytes from patients with metastatic melanoma. PLoS Med. 2007;4:e176.

89. Takahashi Y, Kaneda H, Takasuka N, et al. Enhancement of antiproliferative activity of interferons by RNA interference-mediated silencing of SOCS gene expression in tumor cells. Cancer Sci. 2008;99:1650-1655.

90. Hanada T, Yoshimura A. Regulation of cytokine signaling and inflammation. Cytokine Growth Factor Rev. 2002;13:413-421.

91. Sakai I, Takeuchi K, Yamauchi H, et al. Constitutive expression of SOCS3 confers resistance to IFN-alpha in chronic myelogenous leukemia cells. Blood. 2002;100:2926-2931.

92. Gogas H, Ioannovich J, Dafni U, et al. Prognostic significance of autoimmunity during treatment of melanoma with interferon. $N$ Engl J Med. 2006;354:709-718.

93. Nordlung J, Kirkwood J, Milton BFG, et al. Vitiligo in patients with metastastic melanoma: a good prognostic sign. J Am Acad Dermatol. 1983;689-696. Abstract.

94. Zeuzem S, Welsch C, Herrmann E. Pharmacokinetics of peginterferons. Semin Liver Dis. 2003;23 Suppl 1:23-8.

95. Wang YS, Youngster S, Bausch J, et al. Identification of the major positional isomer of pegylated interferon alpha-2b. Biochemistry. 2000;39:10634-10640.

96. PEG-Intron: Drug Information, Schering Corporation.

97. Glue P, Rouzier-Panis R, Raffanel C, et al. A dose-ranging study of pegylated interferon alfa- $2 \mathrm{~b}$ and ribavirin in chronic hepatitis $\mathrm{C}$. The Hepatitis C Intervention Therapy Group. Hepatology. 2000;32: 647-653.

98. Lindsay KL, Trepo C, Heintges T, et al. A randomized, double-blind trial comparing pegylated interferon alfa- $2 \mathrm{~b}$ to interferon alfa-2b as initial treatment for chronic hepatitis C. Hepatology. 2001;34:395-403.

99. Peg-INFa-2a, Pegasys: Drug Information. www.rocheusa.com products/pegasys/pi.pdf.

100. Algrananti N, Sy S, Mobi M. A branched methoxy $40 \mathrm{kDa}$ polyethylene glykol (PEG) moiety optimizes the pharmakocinetics (PK) of peginterferon a-2a(PEG-IFN)and may explain its enhanced efficacy in chronic hepatitis C (CHC). Hepatology. 1999;190A: Abstract.

101. Balch CM, Buzaid AC, Soong SJ, et al. Final version of the American Joint Committee on Cancer staging system for cutaneous melanoma. J Clin Oncol. 2001;19:3635-48.

102. Dummer R, Panizzon R, Bloch PH, et al. Updated Swiss guidelines for the treatment and follow up of cutaneous melanoma. Dermatology. $2005 ; 39-44$.

103. Kirkwood JM, Ibrahim JG, Sondak VK, et al. High- and low-dose interferon alfa-2b in high-risk melanoma: first analysis of intergroup trial E1690/S9111/C9190. J Clin Oncol. 2000;18:2444-2458.

104. Kirkwood JM, Manola J, Ibrahim J, et al. A pooled analysis of eastern cooperative oncology group and intergroup trials of adjuvant high-dose interferon for melanoma. Clin Cancer Res. 2004;10:1670-167.

105. Eggermont AM, Suciu S, MacKie R, et al. Post-surgery adjuvant therapy with intermediate doses of interferon alfa $2 \mathrm{~b}$ versus observation in patients with stage IIb/III melanoma (EORTC 18952): randomised controlled trial. Lancet. 2005;366:1189-1196.

106. Kirkwood JM, Strawderman MH, Ernstoff MS, et al. Interferon alfa- $2 b$ adjuvant therapy of high-risk resected cutaneous melanoma: the Eastern Cooperative Oncology Group Trial EST 1684. J Clin Oncol. 1996;14:7-17.

107. Eggermont AM, Suciu S, Santinami M, et al. Adjuvant therapy with pegylated interferon alfa- $2 \mathrm{~b}$ versus observation alone in resected stage III melanoma: final results of EORTC 18991, a randomised phase III trial. Lancet. 2008;372:117-126.

108. Dummer R, Garbe C, Thompson JA, et al. Randomized dose-escalation study evaluating peginterferon alfa- $2 \mathrm{a}$ in patients with metastatic malignant melanoma. J Clin Oncol. 2006;24:1188-1194. 
109. Millwald MJ, Bedikian AY, Conry RM, et al. Randomized multinational phase III trial of dacarbazine( DTIC) with or without Bcl-2 antisense (oblimersen sodium) in patients with advnced maligannt melanoma (MM). Analysis of long-term survival. ASCO Annual Meeting: Abstract Nr. 2004;7505.

110. Schadendorf D, Ugurel S, Schuler-Thurner B, et al. Dacarbazine (DTIC) versus vaccination with autologous peptide-pulsed dendritic cells (DC) in first-line treatment of patients with metastatic melanoma: a randomized phase III trial of the DC study group of the DeCOG. Ann Oncol. 2006;17:563-570.

111. Kurokohchi K, Takaguchi K, Kita K, et al. Successful treatment of advanced hepatocellular carcinoma by combined administration of 5-fluorouracil and pegylated interferon-alpha. World J Gastroenterol. 2005;11:5401-5403.

112. Son MJ, Song HS, Kim MH, et al. Synergistic effect and condition of pegylated interferon alpha with paclitaxel on glioblastoma. Int $J$ Oncol. 2006;28:1385-1392.

113. Kaufmann R, Spieth K, Leiter U, et al. Temozolomide in combination with interferon-alfa versus temozolomide alone in patients with advanced metastatic melanoma: a randomized, phase III, multicenter study from the Dermatologic Cooperative Oncology Group. J Clin Oncol. 2005;23:9001-9007.

114. Hwu WJ, Panageas KS, Menell JH, et al. Phase II study of temozolomide plus pegylated interferon-alpha- $2 b$ for metastatic melanoma. Cancer. 2006;106:2445-51.
115. Middleton MR, Grob JJ, Aaronson N, et al. Randomized phase III study of temozolomide versus dacarbazine in the treatment of patients with advanced metastatic malignant melanoma. J Clin Oncol. 2000;18:158-66

116. Spieth K, Kaufmann R, Dummer R, et al. Temozolomide plus pegylated interferon alfa- $2 \mathrm{~b}$ as first-line treatment for stage IV melanoma: a multicenter phase II trial of the Dermatologic Cooperative Oncology Group (DeCOG). Ann Oncol. 2008;19:801-6.

117. Hauschild A, Dummer R, Ugurel S, et al. Combined treatment with pegylated interferon-alpha-2a and dacarbazine in patients with advanced metastatic melanoma: a phase 2 study. Cancer. 2008;113:1404-11.

118. Vaishampayan UN, Heilbrun LK, Marsack C, et al. Phase II trial of pegylated interferon and thalidomide in malignant metastatic melanoma. Anticancer Drugs. 2007;18:1221-6.

119. Medwatch. What is a serious adverse effect? www.fda.gov retrieved on 2007;09-18.

120. Hauschild A, Gogas H, Tarhini A, et al. Practical guidelines for the management of interferon-alpha-2b side effects in patients receiving adjuvant treatment for melanoma: expert opinion. Cancer. 2008;112:982-94.

121. Malik UR, Makower DF, Wadler S. Interferon-mediated fatigue. Cancer. 2001;92:1664-8.

122. Arzneimittel-Kompendium der Schweiz http://www.kompendium.ch/ Copyright by Documed AG, Basel, Switzerland 2008. 